\title{
Free Radical Acylation Approaches of C-H Bonds with 2-Chloroethylsulfonyl Oxime Ethers
}

\author{
Sunggak Kim,* Namsun Kim, Won-jin Chung, Chang Ho Cho
}

Department of Chemistry and Center for Molecular Design and Synthesis, School of Molecular Science, Korea Advanced Institute of Science and Technology, Taejon 305-701, Korea

Fax +82 42 8698370; E-mail: skim@ mail.kaist.ac.kr

Received 17 January 2001

Dedicated to Professor Ryoji Noyori in recognition of his significant contributions to the art of organic synthesis

Abstract: Radical acylations of C-H bonds were successfully accomplished with 2-chloroethylsulfonyl oxime ethers.

Key words: functionalizations, acylations, radical reactions, C-H bonds, chlorine atoms

Functionalization of C-H bonds is of synthetic importance and has attracted a great deal of recent attention among organic chemists. ${ }^{1}$ In general, two approaches involving a radical process and a metal complex-mediated process are usually employed. In a radical process, its characteristic feature is to generate a radical center by cleaving $\mathrm{C}-\mathrm{H}$ bonds inter- or intramolecularly, which allows to functionalize even saturated hydrocarbons under mild conditions. $^{2}$ In this regard, chlorination and hydroxylation of C$\mathrm{H}$ bonds are well studied. ${ }^{2,3}$ For introduction of carbonyl groups to the $\mathrm{C}-\mathrm{H}$ bonds, several reports on radical-mediated chlorocarbonylation ${ }^{4}$ and acylation ${ }^{5}$ appeared. Acylations were achieved using biacetyl ${ }^{5 a}$ and activated aldoximes $^{5 b}$ as radical acceptors. Recently, Fuchs reported alkynylation, alkenylation, and allylation of $\mathrm{C}-\mathrm{H}$ bonds using the corresponding triflones. ${ }^{6}$

In connection with our interest in free radical acylation approaches, ${ }^{7}$ we had occasion to test the possibility of acylation of $\mathrm{C}-\mathrm{H}$ bonds by introducing oxime ether groups with sulfonyl oxime ethers and found that this approach could be successfully accomplished with 2-chloroethylsulfonyl oxime ether $\mathbf{1}$. This radical-mediated process is very attractive because the present approach not only avoids the use of highly toxic organotin compounds and strong acidic or basic conditions but also allows to introduce an oxime ether group with cleaving $\mathrm{C}-\mathrm{H}$ bonds in a single step.

In cleaving $\mathrm{C}-\mathrm{H}$ bonds, the radical process utilizes electrophilic radicals such as an alkoxy radical, a trifluoromethyl radical, and a chlorine atom because those radicals can form rather strong bonds with hydrogen atoms. For radical acylation of $\mathrm{C}-\mathrm{H}$ bonds, two sulfonyl oxime ethers ( $\mathbf{1}$ and $\mathbf{2}$ ) were chosen because the chlorine atom could be generated as shown in Scheme 1. Our approach relies on an alkyl radical addition to 2-chloroethylsulfonyl oxime ether 1 followed by $\beta$-elimination of 2-chloroethylsulfonyl radical which undergoes thermal decomposition to generate the chlorine atom along with the liberation of sulfur dioxide and ethylene. ${ }^{8}$ Although the chlorine atom

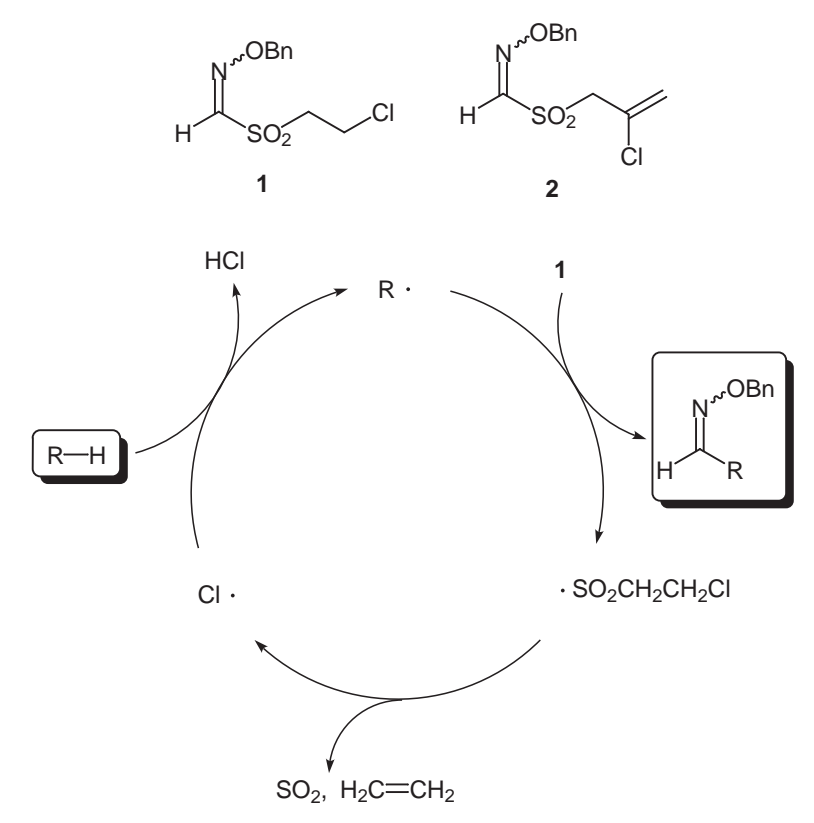

Scheme 1

can cleave $\mathrm{C}-\mathrm{H}$ bonds to generate alkyl radicals along with the formation of $\mathrm{HCl}$, we assumed that the electrophilic chlorine atom would not attack 1 to afford $O$-benzylformohydroximoyl chloride (3) along with the liberation of 2-chloroethylsulfonyl radical.

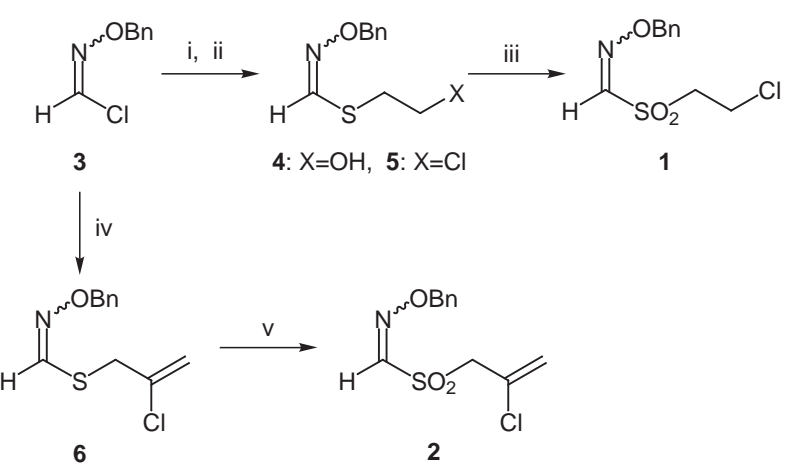

Scheme 2 (i) $\mathrm{NaH}, \mathrm{HSCH}_{2} \mathrm{CH}_{2} \mathrm{OH}$, THF, $1.5 \mathrm{~h}, 85 \%$; (ii) $\mathrm{PPh}_{3}$, NCS, $\mathrm{CH}_{2} \mathrm{Cl}_{2}, 3 \mathrm{~h}, 93 \%$; (iii) $\mathrm{SeO}_{2}, 30 \% \mathrm{H}_{2} \mathrm{O}_{2}, \mathrm{MeOH}, 24 \mathrm{~h}, 63 \%$; (iv) $\mathrm{AcSCH}_{2} \mathrm{C}(\mathrm{Cl})=\mathrm{CH}_{2}, \mathrm{NaOMe}, \mathrm{MeOH}, 0.5 \mathrm{~h}, 76 \%$; (v) oxone, $\mathrm{MeOH} / \mathrm{H}_{2} \mathrm{O}, 7$ h, $63 \%$ 
The preparation of $\mathbf{1}$ and $\mathbf{2}$ is summarized in Scheme 2. $\mathbf{3}$ was treated with sodium salt of 2-mercaptoethanol in THF at room temperature for $1.5 \mathrm{~h}$ to afford 2-hydroxyethylthio oxime ether 4 in $85 \%$ yield. 4 was reacted with triphenylphosphine and $\mathrm{N}$-chlorosuccinimide in dichloromethane for $3 \mathrm{~h}$ to give 2-chloroethylthio oxime ether 5 in $93 \%$ yield and $\mathbf{5}$ was further oxidized with $\mathrm{SeO}_{2}$ and $30 \%$ hydrogen peroxide in methanol for $24 \mathrm{~h}$ to give 2 -chloroethylsulfonyl oxime ether $\mathbf{1}$ in $63 \%$ yield. ${ }^{9} \mathbf{2}$ was prepared by the reaction of $\mathbf{3}$ with sodium salt of 2-chloroallylmercaptan in methanol for $0.5 \mathrm{~h}$ and subsequent oxidation of $\mathbf{6}$ with oxone in aqueous methanol for $7 \mathrm{~h}$.

Table Radical acylation of C-H bonds with $\mathbf{1}$

condition ${ }^{a}$

${ }^{a}$ Method A: neat substrate, $10 \%$ V-40, reflux; Method B: neat substrate, $300 \mathrm{~nm}$; Method C: 10 equiv of substrate, $\mathrm{C}_{6} \mathrm{H}_{6}, 300 \mathrm{~nm}$ ${ }^{\mathrm{b}}$ The yield was not optimized.

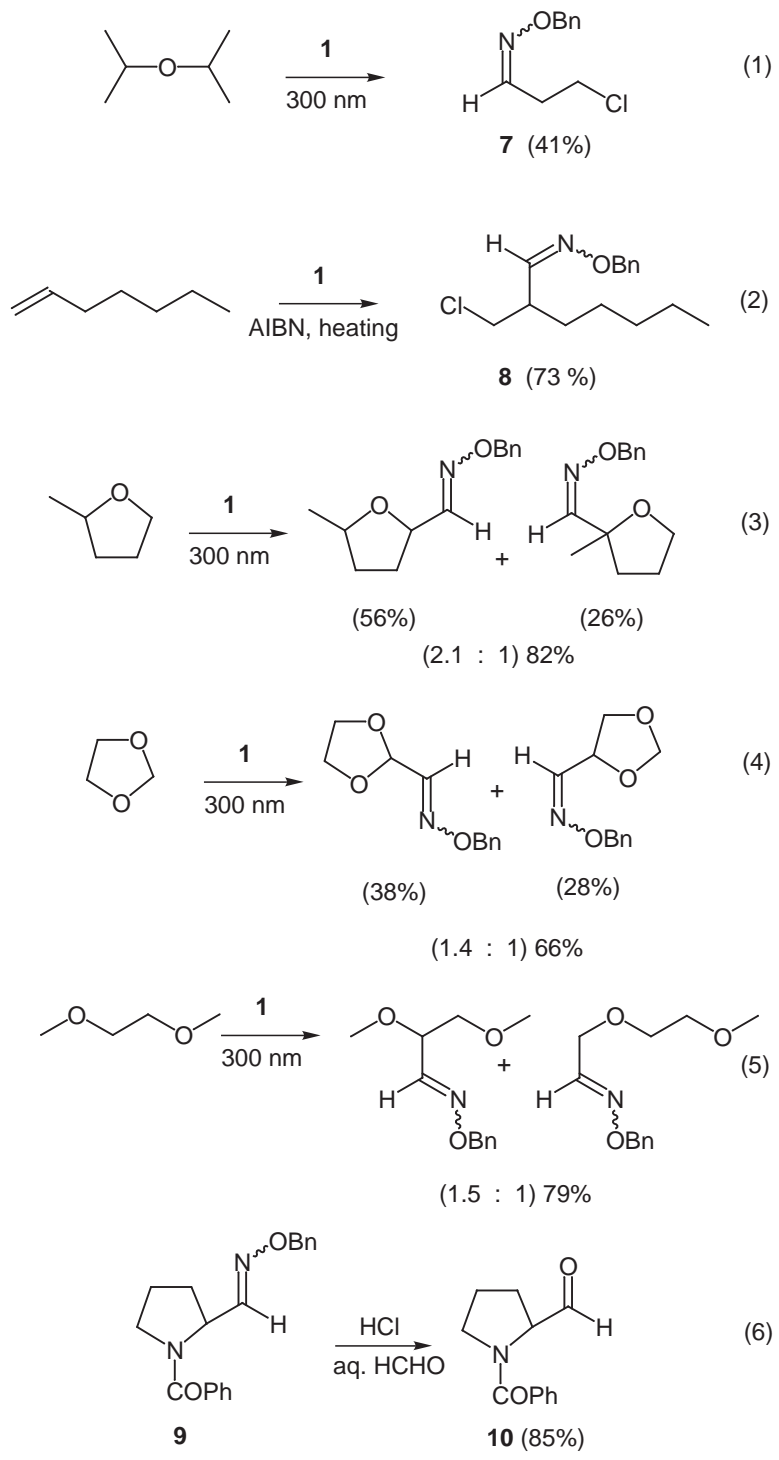

Equations 1-6

Reaction of $\mathbf{1}$ in refluxing 1,4-dioxane using V-40 as a radical initiator for $48 \mathrm{~h}$ gave the desired oxime ether in $75 \%$ yield (Method A). When the same reaction was carried out with 2 under the same conditions, the yield was somewhat lower (60\%). In addition, 2 was thermally unstable and underwent decomposition to some extent upon heating. Thus, remaining reactions were carried out with 1. The similar reaction in refluxing tetrahydrofuran for $30 \mathrm{~h}$ gave the corresponding oxime ether in $52 \%$ yield. During the course of our investigation, somewhat surprisingly, we found that the present reaction could be successfully carried out under photochemically initiated conditions (Method B) ${ }^{10}$ The yield was increased and the reaction time was significantly shortened under the photochemically initiated condition. When a solution of $\mathbf{1}$ in 1,4-dioxane was irradiated at $300 \mathrm{~nm}$ for $12 \mathrm{~h}$, the desired oxime ether was isolated in $79 \%$ yield. As shown in Table, reactions with cyclic and acyclic ethers under photochemically initiated conditions resulted in the formation of $\alpha$ - 
oxime ether substituted ethers in high yields. A similar result was obtained with somewhat sterically hindered 2,5dimethyltetrahydrofuran. In contrast, diisopropyl ether did not react with 1 and latter was converted into 2-chloroethyl oxime ether resulting from the addition of chloroethyl radical to $\mathbf{1}$ (eq 1). With tetrahydrothiophene, the reaction was relatively slow and the yield was somewhat lower. In the case of 1-heptene, the reaction was messy under photochemically initiated conditions. When a solution of 1 in 1-heptene in the presence of AIBN as an initiator was refluxed for $14 \mathrm{~h}$, the chlorine atom did not abstract a hydrogen atom to generate an allyl radical but added to an alkenyl bond to afford $\mathbf{8}$ in $73 \%$ yield (eq 2).

When the substrate was a solid or a high boilng liquid, the reaction was carried out with a large excess amount of the substrate (10 equiv) in benzene at $300 \mathrm{~nm}$ (Method C). ${ }^{11}$ Irradiation of $N$-benzoyl-pyrrolidine (10 equiv) in benzene at $300 \mathrm{~nm}$ for $48 \mathrm{~h}$ afforded pyrrolidinyl oxime ether 9 in $75 \%$ yield. The use of $N$-benzoyl-pyrrolidine (3 equiv) under the same condition gave a lower yield (57\%). Similarly, unactivated hydrocarbons such as adamantane and 1,2,3,4-tetrahydronaphthalene were functionalized as the oxime ether derivatives. In an effort to examine the regioselectivity of the reaction, three unsymmetrical ethers were investigated. A low regioselectivity was observed with 2-methyltetrahydrofuran, yielding approximately a 2:1 mixture of two products (eq 3). Similarly, 1,3-dioxolane and dimethoxyethane gave lower regioselectivities due to an intrinsic property of radical reactions (eqs 4 and $5)$. An oxime ether group could be hydrolyzed into an aldehyde group under the acidic conditions (eq 6). Treatment of 9 with $\mathrm{HCl}$ in aqueous $\mathrm{HCHO}$ at room temperature for $3 \mathrm{~h}$ gave $\mathbf{1 0}$ in $85 \%$ yield.

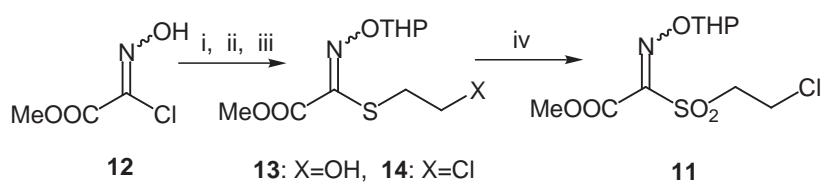

Scheme 3 (i) DHP, TsOH, $\mathrm{CH}_{2} \mathrm{Cl}_{2}, 0.5 \mathrm{~h}, 93 \%$; (ii) $\mathrm{HSCH}_{2} \mathrm{CH}_{2} \mathrm{OH}$ NaOMe; MeOH, 5 h; (iii) NCS, $\mathrm{PPh}_{3}, \mathrm{CH}_{2} \mathrm{Cl}_{2}, 0-25^{\circ} \mathrm{C}, 1 \mathrm{~h}, 68 \%$ from 12; (iv) $m$-CPBA, $\mathrm{NaHCO}_{3}, \mathrm{CH}_{2} \mathrm{Cl}_{2}, 10 \mathrm{~h}, 68 \%$

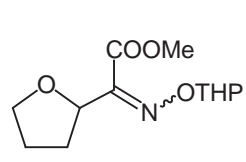

$15(67 \%)$<smiles>CCOC(C)/C(=N\[OH2+])C(OC)OC</smiles>

$17(72 \%)$

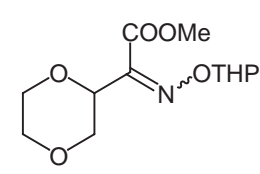

$16(64 \%)$<smiles>COC(=O)/C(COC(C)(C)C)=N\[OH+]</smiles>

$18(81 \%)$
As an extension of this work, ${ }^{12}$ we briefly studied the possibility of introducing an $\alpha$-keto ester group to the $\mathrm{C}-\mathrm{H}$ bonds by use of carbomethoxy derivative 11. ${ }^{13}$ As shown in Scheme 3, 11 was readily prepared by a four-step sequence from previously known compound 12. ${ }^{14}$ Irradiation of a solution of $\mathbf{1 1}$ in tetrahydrofuran at $300 \mathrm{~nm}$ for 24 $\mathrm{h}$ afforded tetrahydrofuranyl oxime ether $\mathbf{1 5}$ in $67 \%$ yield. Similar results were obtained with 1,4-dioxane, diethyl ether, and $t$-butyl methyl ether to give 16, 17, and 18 in good yields, respectively.

In conclusion, we have demonstrated that 2-chloroethylsulfonyl oxime ether $\mathbf{1}$ and $\mathbf{1 1}$ are effective for radical acylations of $\mathrm{C}-\mathrm{H}$ bonds, thereby introducing a formyl group and a $\alpha$-keto ester group.

\section{Acknowledgement}

This research was supported by the Center for Molecular Design and Synthesis (CMDS) and BK 21 project.

\section{References and Notes}

(1) For reviews, see: Hill, C. L. Activation and Functionalization of Alkanes; Academic Press: New York, 1989. Shilov, A. E.; Shul'pin, G. B. Chem. Rev. 1997, 97, 2879. Dyker, G. Angew. Chem. Int. Ed. 1999, 38, 1699.

(2) Jossey, F.; Kefirt, D.; Sorba, J. Free Radicals in Organic Chemistry; John Wiley \& Sons: Masson 1995, pp 211-220. Freidlina, R. K.; Terent'ev, A. B. Adv. Free Radical Chem. 1980, 6,1 .

(3) Crabtree, R. H.; Habib, A. In Comprehensive Organic Synthesis; Ley, S. V., Vol. Ed.; Trost, B. M., Fleming, I., Series Eds.; Pergamon Press: New York, 1991; Vol. 7, pp 120. Meunier, B. Chem. Rev. 1992, 92, 1411. Busch, D. H.; Alcock, N. W. Chem. Rev. 1994, 94, 585.

(4) Kharasch, M. S.; Brown, H. C. J. Am. Chem. Soc. 1942, 64, 329. Kharasch, M. S.; Kane, S. S.; Brown, H. C. J. Am. Chem. Soc. 1942, 64, 1621. Tabushi, I.; Hamuro, J.; Oda, R. J. Org. Chem. 1968, 33, 2108.

(5) (a) Bentrude, W. G.; Darnall, K. R. J. Am. Chem. Soc. 1968, 90, 3588. (b) Citterio, A.; Filippini, L. Synthesis 1986, 473.

(6) (a) alkynylation: Gong, J.; Fuchs, P. L. J. Am. Chem. Soc. 1996, 118, 4486. Gong, J.; Fuchs, P. L. Tetrahedron Lett. 1997, 38, 787. (b) alkenylation: Xiang, J.; Fuchs, P. L. J. Am. Chem. Soc. 1996, 118, 11986. Xiang, J.; Jiang, W.; Gong, J.; Fuchs, P. L. J. Am. Chem. Soc. 1997, 119, 4123. (c) allylation: Xiang, J.; Evarts, J.; Rivkin, A.; Curran, D. P.; Fuchs, P. L. Tetrahedron Lett. 1998, 39, 4163. Tanko, J. M.; Sadeghipour, M. Angew. Chem. Int. Ed. 1999, 38, 159.

(7) Kim, S.; Lee, I. Y.; Yoon, J-Y.; Oh, D. H. J. Am. Chem. Soc. 1996, 118, 5138. Kim, S.; Yoon, J-Y. J. Am. Chem. Soc. 1997, 119, 5982. Kim, S.; Lee, I. Y. Tetrahedron Lett. 1998, 39, 1587. Ryu, I.; Kuriyama, H.; Minakata, S.; Komatsu, M.; Yoon, J-Y.; Kim, S. J. Am. Chem. Soc. 1999, 121, 12190. Kim, S.; Kim, N.; Yoon, J-Y.; Oh, D. H. Synlett 2000, 1148.

(8) Chatgilialoglu, C. In The Chemistry of Sulfones and Sulfoxides; Patai, S., Rappoport, Z., Stirling, C. J. M., Eds.; Wiley: Chichester, 1988; pp 1089-1113. Bertrand, M. Org. Prep. Proc. Int. 1994, 26, 257. Guyader, F. L.; Quiclet-Sire, B.; Seguin, S.; Zard, S. Z. J. Am. Chem. Soc. 1997, 119, 7410.

(9) $O$-Benzyl-1-(2-chloroethylsulfonyl)-formaldoxime (1) ${ }^{1} \mathrm{H}$ $\mathrm{NMR}\left(\mathrm{CDCl}_{3}, 300 \mathrm{MHz}\right) \delta 3.60-3.65(\mathrm{~m}, 2 \mathrm{H}), 3.70-3.75(\mathrm{~m}$, 2H), $5.32(\mathrm{~s}, 2 \mathrm{H}), 7.26(\mathrm{~s}, 1 \mathrm{H}), 7.34-7.38(\mathrm{~m}, 5 \mathrm{H}) ;{ }^{13} \mathrm{C} \mathrm{NMR}$ $\left(\mathrm{CDCl}_{3}, 300 \mathrm{MHz}\right) \delta 35.3,57.4,79.4,128.5,128.8,128.9$, 
135.0, 142.8; IR (NaCl) 3039, 1454, 1331, 1140, 1125, 1012 $700 \mathrm{~cm}^{-1}$; HRMS $\left(\mathrm{M}^{+}\right)$calcd for $\mathrm{C}_{10} \mathrm{H}_{12} \mathrm{ClNO}_{3} \mathrm{~S}$ : 261.0226, found 261.0232 .

(10) (Method B) The mixture of $\mathbf{1}(52 \mathrm{mg}, 0.2 \mathrm{mmol}$ ) and 1,4-dioxane $(1.2 \mathrm{~mL})$ was degassed for $20 \mathrm{~min}$ and the solution was irradiated at $300 \mathrm{~nm}$ in a Rayonet photochemical reactor at room temperature for $12 \mathrm{~h}$. After the reaction was complete, the reaction mixture was concentrated under reduced pressure and the residue was purified by flash column chromatography on silica gel using ethyl acetate: $n$ hexane $=1: 10$ solution to give $35 \mathrm{mg}(79 \%)$ of product. ${ }^{1} \mathrm{H}$ NMR $\left(\mathrm{CDCl}_{3}, 300 \mathrm{MHz}\right) E: Z=7: 3 ; \delta 3.29-3.79(\mathrm{~m}, 6 \mathrm{H})$, 4.17-4.19 (m, 0.7H), 4.71-4.74 (m, 0.3H), $5.04(\mathrm{~s}, 2 \mathrm{H}), 6.59$ $6.60(\mathrm{~d}, 0.3 \mathrm{H}, \mathrm{J}=4.6 \mathrm{~Hz}), 7.23-7.31(\mathrm{~m}, 5.7 \mathrm{H}) ;{ }^{13} \mathrm{C} \mathrm{NMR}$ $\left(\mathrm{CDCl}_{3}, 300 \mathrm{MHz}\right) \delta 66.20,66.27,66.50,66.64,66.68,71.21$, 72.77, 76.32, 76.50, 128.02, 128.07, 128.33, 128.42, 128.45, 137.04, 137.29, 147.13, 148.83; IR ( NaCl) 3034, 2964, 2864, 1497, 1454, 1368, 1280, 1118, 1027, $979 \mathrm{~cm}^{-1}$; HRMS (M+) calcd for $\mathrm{C}_{12} \mathrm{H}_{15} \mathrm{NO}_{3}: 221.1052$, found 221.1053.

(11) (Method C) A benzene solution (1 mL) of $1(52 \mathrm{mg}, 0.2 \mathrm{mmol})$ and adamantane $(272 \mathrm{mg}, 2 \mathrm{mmol})$ in quartz tube was degassed for $20 \mathrm{~min}$ and the solution was irradiated at $300 \mathrm{~nm}$ in a Rayonet photochemical reactor at room temperature for $22 \mathrm{~h}$. After the reaction was complete, the reaction mixture was concentrated under reduced pressure. The residue was purified by flash column chromatography on silica gel using ethyl acetate: $n$-hexane $=1: 30$ as an eluant to give the product (39 mg, 72\%). ${ }^{1} \mathrm{H}$ NMR $\left(\mathrm{CDCl}_{3}, 300 \mathrm{MHz}\right) \delta 1.70(\mathrm{bs}, 13 \mathrm{H})$ 1.99 (bs, 2H), 5.03 (s, 2H), 7.20 (s, 1H), 7.29-7.36 (m, 5H); ${ }^{13} \mathrm{C}$ NMR $\left(\mathrm{CDCl}_{3}, 300 \mathrm{MHz}\right) \delta 27.9,35.6,36.6,40.0,75.5$, 127.7, 128.2, 128.3, 137.7, 158.7; IR ( NaCl) 2911, 2850, $1451,1366,1039 \mathrm{~cm}^{-1}$; HRMS $\left(\mathrm{M}^{+}\right)$calcd for $\mathrm{C}_{18} \mathrm{H}_{23} \mathrm{NO}$ : 269.1780, found 269.1786 .

(12) Kim, S.; Yoon, J-Y.; Lee, I. Y. Synlett 1997, 475. Jeon, G-H.; Yoon, J-Y.; Kim, S.; Kim, S. S. Synlett 2000, 128.

(13) (2-Chloroethylsulfonyl)-[(tetrahydropyran-2-yloxyimino)]acetic acid methyl ester $(11){ }^{1} \mathrm{H}$ NMR $\left(\mathrm{CDCl}_{3}, 300 \mathrm{MHz}\right) \delta$ $1.55-1.96(\mathrm{~m}, 6 \mathrm{H}) 3.62-3.89(\mathrm{~m}, 6 \mathrm{H}) 3.90(\mathrm{~s}, 3 \mathrm{H}) 5.54(\mathrm{t}, 1 \mathrm{H}$, $\mathrm{J}=2.8 \mathrm{~Hz}) ;{ }^{13} \mathrm{C} \mathrm{NMR}\left(\mathrm{CDCl}_{3}, 300 \mathrm{MHz}\right) \delta 18.20,24.58$, 27.83, 35.06, 53.91, 58.32, 62.59, 104.35, 146.22, 158.83; IR(NaCl) 763, 819, 872, 894, 943, 1000, 1038, 1083, 1133, 1154, 1208, 1292, 1341, 1438, 1560, 1744, $2956 \mathrm{~cm}^{-1}$.

(14) Kozikowski, A. P.; Adamczyk, M. J. Org. Chem. 1983, 48, 366.

Article Identifier:

1437-2096,E;2001,0,SI,0937,0940,ftx,en;Y01301ST.pdf 